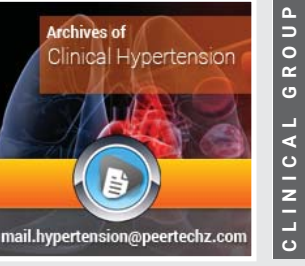

\section{Renal denervation- its current status \& future prospects for management of Hypertension}

\author{
Sreenivas Kumar Arramraju ${ }^{1 *}$ and Rama Krishna Janapati ${ }^{2}$ \\ 'Senior Consultant cardiologist, Director, Cardiology \& Clinical Research, Apollo Hospitals, Apollo \\ Health City, Jubilee Hills, Hyderabad, India \\ ${ }^{2}$ Consultant Cardiologist, Apollo Health City. Jubilee Hills, Hyderabad, India
}

Received: 29 August, 2020

Accepted: 02 September, 2020

Published: 03 September, 2020

*Corresponding author: Sreenivas Kumar Arramraju, MD, DM, FACC (USA), Director, Cardiology \& Clinical Research, Apollo Hospitals, Apollo Health City, Jubilee Hills, Hyderabad, FACTS Foundation \& FPS, India, Tel: 040 23607777, 98480 46785,

E-mail: arramraj@yahoo.com

https://www.peertechz.com

Check for updates

\section{Introduction}

Hypertension is one of the major contributing factor for global burden of cardiovascular morbidity and mortality. It was estimated that 1.13 billion people were affected worldwide and most of them are residing in low and middle income countries [1]. Hypertension was strongly associated with coronary artery disease, cerebrovascular events and peripheral artery disease. The pathogenesis of hypertension is multifactorial and sympathetic nervous system hyperactivity is one of the contributing factor for development and poor control of blood pressure [2]. Oral medications are the mainstay of therapy for hypertension but however around $50 \%$ of patients were non adherent to prescribed medication at 1 year follow up [3]. Despite the availability of multiple classes of effective drugs for treatment of Hypertension a large number of patients were not attaining the recommended blood pressure goals. There were multiple reasons for the poor control of Blood pressure like drug non adherence, drug resistance and improper treatment protocols. We need more complementary alternative treatment modalities for effective treatment of Hypertension [4]. The Renal denervation was one such therapy which was done with various energy sources like Radiofrequency energy, ultrasound energy ablation or chemical ablation with Alcohol [4]. Activation of renal efferent nerves leads to renal artery vasoconstriction,reduced renal blood flow there by leading to activation of renin angiotensin system with increased renin secretion and salt and water retension $[4,5]$. The stimulation of renal afferent nerves leads to activation of central sympathetic activity there by leading to adverse cardio metabolic systemic effects .The renal denervation allows ablation of both efferent and afferent sympathetic nerves there by leading to reduced sympathetic drive to and from the renal arteries [6]. Such procedures if done effectively and with long term good follow up results are likely to prevent the target organ damage and the possible cardiovascular events secondary to uncontrolled hypertension. The outcomes would also not be dependant on individual patient drug compliance and would also avoid side effects of the medication.

\section{Evolution of renal denervation}

The Renal denervation therapy has provided much hope with initial SYMPLICITY HTN1 AND 2 trials $[7,8]$ with double digit blood pressure reduction in office $\mathrm{BP}$, but the sham controlled SYMPLICITY HTN 3 [9], trial did not provide any added advantage with RDN when compared with medical therapy alone [10]. Post hoc analysis of the SYMPLICITY HTN 3 trial found that several limitations like inadequate ablation technique,frequent uncontrolled changes in prescribed medication and heterogenecity of operator experience in ablation techniques had hampered the benefits of the RDN $[10,11]$.

The resurgence of RDN - the new technical principles of ablation

Since then learnings from shortcomings of SYMPLICITY HTN 3 trial, with improved study designs ,redesigned ablation catheters and more homogenous population newer trials were initiated to re-evaluate RDN for Hypertension. With careful analysis of the nerve innervation patterns in animal models we now know that we need to target distal renal artery branches rather than proximal bigger vessels and also need to ablate at multiple sites within arteries in a helical manner rather than 
circumferentially at a single level. This has become possible now as the newer ablation catheters because of their modified designs can be deployed over a thin a guide wire and will become helical once the guide wire is withdrawn before delivering radio frequency energy for ablation.

\section{RDN - Newer clinical trials}

Spiral HTN on med study: The results of the recently published studies were encouraging as they showed a realistic consistent reduction of blood pressure. The SPIRAL HTN ON MED study randomised patients who were already on antihypertensive drugs to either RDN or sham procedure .At the end of 6 months the RDN arm group showed a $7.4 \mathrm{mmHg}$ $\mathrm{BP}$ reduction in ambulatory $\mathrm{BP}$ and $6.8 \mathrm{mmHg}$ reduction in Office Blood pressure [12].

The spiral HTN Off med study: This study included patients who were drug naive to either RDN or sham procedure. At 3 months follow up there was a $7.7 \mathrm{mmHg}$ reduction in office systolic Blood pressure and $5 \mathrm{~mm} \mathrm{Hg}$ reduction in $24 \mathrm{hr}$ Ambulatory BP [13].

The radiance - HTN solo study: This study randomised hypertensive patients to either RDN with Ultrasound energy or Sham procedure. At 2 months follow up ambulatory BP was reduced by $6.3 \mathrm{mmHg}$ and $6.5 \mathrm{mmHg}$ reduction in office Blood pressure. At 6 moths follow up also RDN group had a sustained reduction in blood pressure and RDN group patients were on fewer number of anti hypertensive drugs when compared to sham procedure [14]. These newer studies established the efficacy and safety of RDN in low risk uncomplicated patients with very low incidence of procedure related complications like new renal artery stenosis which was seen only in $0.3 \%$ of patients after RDN.

Global symplicity registry: This registry observed that there was consistent reduction in blood pressure in the range of 8.6 to $10.4 \mathrm{~mm} \mathrm{Hg}$ seen across all high-risk subgroups, including those with resistant hypertension ,older patients , type 2 diabetes, isolated systolic hypertension, chronic kidney disease, and Atrial-fibrillation ( $P<0.0001$ for all). The sustained reductions were seen in patients at all baseline levels of atherosclerotic cardiovascular disease (ASCVD) risk scores. The investigators divided patients according to baseline ASCVD risk ( $<10 \%, 10 \%$ to $<20 \%$, and $20 \%$ or more) and found that BP declined after denervation in all of the groups. At 3 years, the drops in 24-hour systolic BP were 8.6, 6.0, and 7.6 mm Hg across the three risk groups, respectively.This registry data also proved that renal denervation had achieved a sustained,modest systolic BP reduction among real world populatio [15]. A decrease of $10 \mathrm{mmHg}$ in office $\mathrm{BP}$ is related to a relative risk reduction for total mortality of $13 \%$,cardiovascular diseases of $-17 \%$, heart failure of $-28 \%$, and cardio vascular event rate of $-20 \%[16]$.

Radiance-HTN trio and require trials: These two randomised studies are underway to assess the safety and efficacy of ultrasound based RDN in patients with uncontrolled HTN [17].

\section{Future prospects}

Methods to assess effective ablation post procedure: We need to have reliable methods to test the adequacy of RDN procedure on table, so that results will be uniform and reproducible across spectrum of all patients. This is an active area for further research .Various methods had been proposed like direct neural stimulation with selective ablation of pressor sites, reflex elicitation before and after RDN during the index procedure ,and passive monitoring like renal Norepinephrine spillover [18]. Animal studies had shown that regrowth of both afferent and efferent renal sympathetic nerves after RDN there by evading the benefits of RDN [19]. The long term sustainability of benefits of RDN needs to be studied further in human trials .The device based therapies like RDN with Radio-frequency or Ultrasound based ablation therapies will soon be incorporated in to wide spread clinical practice. But the number of issues remain to be determined, like optimal location of ablation sites , energy dosage, penetration depth as well as long-term outcome and efficacy.

Methods to assess hypertensive patient responders immediately and on long term follow up: We should try \& identify newer parameters to determine as to which patient will respond to RDN therapy immediately and why some patients have a delayed response to RDN. It is not clear if functional reinnervation occurs after RDN and how this might affect the BP response. Furthermore research is needed to provide evidence of the effectiveness of RDN treatment for heart failure, insulin resistance, obstructive sleep apnea, atrial fibrillation, endstage renal disease and mild-resistant hypertension. Finally, further research is warranted to provide data on the effect of RDN on morbidity and mortality in patients with resistant hypertension or other diseases [6]. However the optimum patient selection, renewed devices ,adequate renal nerve ablation techniques, adequate training of operators, cost effectiveness and long term durability of the results are the key to success of resurgence of RDN.

\section{Summary}

The results of recent sham controlled trials were promising in reducing the blood pressure in Hypertensive patients. The Device based therapies for Hypertension needs further validation in a large group of selected patients to unfold the true future potential of these therapies.RDN therapy is currently to be done only in select group of patients with compassionate grounds and is not recommended temporarily for routine clinical use.

\section{References}

1. Solomonica A, Lavi S, Choudhury T, Bagur T (2018) Renal denervation therapy beyond resistant hypertension. J Thorac Dis 10: 707-713. Link: https://bit.ly/2Z3sJJL

2. Esler M (2014) Sympathetic nervous system moves toward center stage in cardiovascular medicine: from Thomas Willis to resistant hypertension. Hypertension 63: e25-e32. Link: https://bit.ly/2GqHfVt

3. Blaschke TF, Osterberg L, Vrijens B, Urquhart J (2012) Adherence to medications: insights arising from studies on the unreliable link between

Citation: Arramraju SK, Janapati RK (2020) Renal denervation- its current status \& future prospects for management of Hypertension. Arch Clin Hypertens 6(1): 019-021. 
prescribed and actual drug dosing histories. Annu Rev Pharmacol Toxicol 52 275-301. Link: https://bit.ly/31RiPwo

4. Weber MA, Mahfoud F, Schmieder RE, et al. (2019) Renal Denervation for Treating Hypertension. Current Scientific and Clinical Evidence. J Am Coll Cardiollntv 12: 1095-1105. Link: https://bit.ly/3bldjW2

5. Joyner MJ, Charkoudian N, Gunnar Wallin B (2010) Sympathetic Nervous System and Blood Pressure in Humans. Hypertension 56: 10-16. Link: https://bit.ly/3bkN6a2

6. CVS Ram, AS Kumar (2014) Renal denervation therapy for resistant hypertension:a clinical update. Journal of Human Hypertension 28: 1-6. Link: https://go.nature.com/2Gp2GpU

7. Krum H, Schlaich M, Whitbourn R, Sobotka PA, Sadowski J, et al. (2009) Catheter-based renal sympathetic denervation for resistant HTN: a multicentre safety and proof-of-principle cohort study. Lancet 373: 1275-1281. Link: https://bit.ly/2GpOnBr

8. Esler MD, Krum H, Sobotka PA, Schlaich MP, Schmieder RE, et al. (2010) Rena sympathetic denervation in patients with treatment-resistant HTN (the SYMPLICITY HTN-2 trial): a randomised controlled trial. Lancet 376: 19031909. Link: https://bit.ly/3IMT8VZ

9. Bhatt DL, Kandzari DE, O'Neill WW, D’Agostino R, Flack JM, et al. (2014) A controlled trial of renal denervation for resistant hypertension. $\mathrm{N}$ Engl $\mathrm{J}$ Med 370: 1393-1401. Link: https://bit.ly/31TRbil

10. Ram VCS (2019) Status of Renal Denervation Therapy for Hypertension. Circulation 139: 601-603. Link: https://bit.ly/32W1TUQ

11. Azizi M, Sapoval M, Gosse P, Monge M, Bobrie G, et al. (2015) Optimum and stepped care standardised antihypertensive treatment with or without renal denervation for resistant hypertension (DENERHTN): a multicentre, open-label, randomised controlled trial. Lancet 385: 1957-1965. Link: https://bit.ly/2EJKMxK

12. Kandzari DE, Bohm M, Mahfoud F, Townsend RR, Weber MA, et al. (2018)
Effect of renal denervation on blood pressure in the presence of antihypertensive drugs: 6-month efficacy and safety results from the SPYRAL HTN-ON MED proof-of-concept randomised trial. Lancet 391: 2346-2355. Link: https://bit.ly/2GiAJQo

13. Townsend RR, Mahfoud F, Kandzari DE, Kario K, Pocock S, et al. (2017) Catheter-based renal denervation in patients with uncontrolled hypertension in the absence of antihypertensive medications (SPYRAL HTN-OFF MED): a randomised, sham-controlled, proof-of-concept trial. Lancet 390: 2160-2170. Link: https://bit.ly/3jEAGNi

14. Azizi M, Schmieder RE, Mahfoud F, Weber MA, Daemen J, et al. (2019) Sixmonth results of treatment-blinded medication titration for hypertension control following randomization to endovascular ultrasound renal denervation or a sham procedure in the RADIANCE-HTN SOLO trial. Circulation. Link: https://bit.ly/3IMvRTN

15. Mahfoud F, Mancia G, Schmieder R, Narkiewicz K, Ruilope L, et al. (2020) Renal Denervation in High-Risk Patients with Hypertension. J Am Coll Cardiol 75: 2879-2888. Link: https://bit.ly/3IEODN7

16. Ettehad D, Emdin CA, Kiran A, Anderson SG, Callender T, et al. (2016) Blood pressure lowering for prevention of cardiovascular disease and death: a systematic review and meta-analysis. Lancet 387: 957-967. Link: https://bit.ly/32L86Tq

17. Mauri L, Kario K, Basile J, Daemen J, Davies J, et al. (2018) A multinationa clinical approach to assessing the effectiveness of catheter-based ultrasound renal denervation: The RADIANCE-HTN and REQUIRE clinical study designs. Am Heart J 198: 115-129. Link: https://bit.ly/351tUgE

18. Kiuchi MG, Esler MD, Fink GD, Osborn JW, Banek CT, et al. (2019) Rena Denervation Update From the International Sympathetic Nervous System Summit. J Am Coll Cardiol 73: 3006-301 7. Link: https://bit.ly/2GqEbIX

19. Booth LC, Nishi EE, Yao ST, Ramchandra R, Lambert GW, et al. (2015) Reinnervation of renal afferent and efferent nerves at 5.5 and 11 months after catheter-based radiofrequency renal denervation in sheep. Hypertension 65 393-400. Link: https://bit.ly/3jTc0kr

\section{Discover a bigger Impact and Visibility of your article publication with} Peertechz Publications

Highlights

* Signatory publisher of ORCID

* Signatory Publisher of DORA (San Francisco Declaration on Research Assessment)

* Articles archived in worlds' renowned service providers such as Portico, CNKI, AGRIS, TDNet, Base (Bielefeld University Library), CrossRef, Scilit, J-Gate etc.

* Journals indexed in ICMJE, SHERPA/ROMEO, Google Scholar etc.

* OAI-PMH (Open Archives Initiative Protocol for Metadata Harvesting)

* Dedicated Editorial Board for every journal

* Accurate and rapid peer-review process

* Increased citations of published articles through promotions

* Reduced timeline for article publication

Submit your articles and experience a new surge in publication services (https://www.peertechz.com/submission).

Peertechz journals wishes everlasting success in your every endeavours.

Copyright: () 2020 Arramraju SK, et al. This is an open-access article distributed under the terms of the Creative Commons Attribution License, which permits unrestricted use, distribution, and reproduction in any medium, provided the original author and source are credited. 